\title{
Concurso Miss Mulata Rio Grande do Sul: o conflito da cor e a branquitude nos padrões estéticos
}

\author{
Competition Miss Mulata Rio Grande do Sul: the conflict of color and \\ whiteness in aesthetic standards
}

\author{
Beatriz Floôr Quadrado ${ }^{1}$ \\ 1biafloor@yahoo.com.br, Universidade Federal de Pelotas
}

\begin{abstract}
Resumo
O trabalho de pesquisa tem como temática o concurso de beleza intitulado "Miss Mulata" da cidade de Arroio Grande, região sul do Rio Grande do sul. O concurso tem origem em 1969 e seu último ano de realização foi 1999, sendo que em 1989 deixa de abranger apenas a região sul para se tornar Estadual. O principal objetivo da pesquisa é entender o uso da terminologia "mulata" para o concurso junto à identidade, do grupo envolvido; mas também levando em consideração épocas, histórias e a diversidade dos grupos negros. Por isso, a necessidade de uma análise da relação de beleza, gênero e raça para entender a relevância do concurso para as mulheres negras da cidade de Arroio Grande, junto à dominação do padrão estético da branquitude. A principal metodologia do trabalho é a Historia Oral. Enfim, levar-se em conta, nesta pesquisa, que o concurso Miss Mulata analisado é uma forma de estratégia étnico-social, de re-apropriação de significados, além de uma forma valorização e auto-estima do grupo envolto no concurso.
\end{abstract}

Palavras- chave: Mulata; negritude; branquitude; cor; estética

\begin{abstract}
The research work has as a theme the beauty pageant called "Miss Mulata" the city of Arroio Grande, south of the Rio Grande do Sul region. The competition originated in 1969 and its last profitable year was 1999 and in 1989 leaves only cover the southern region to become State. The main objective of the research is to understand the use of the term "mulata" for the contest with the identity of the group involved; but also taking into account times, stories and diversity of black groups. Therefore, the need for a nalysis of the beauty of relationship, gender and race to understand the relevance of the competition for black women of the city of Arroio Grande, next to the domination of the aesthetic standard of whiteness. The principal methodology of work is the Oral History. It is important to take into account that the Miss Mulata contest is considered a form of ethnic and social strategy of re-appropriation of meanings, as well as a way recovery and self-esteem wrapped group in the competition.
\end{abstract}

Keywords: Mulata; blackness; whiteness; color; aesthetics

\section{Um concurso de beleza negra}

O concurso de beleza Miss Mulata tem origem em Arroio Grande em 1969. A cidade localiza-se próximo a fronteira com o Uruguai, é conhecida como Cidade Simpatia por acolher bem quem vem de outras localidades, no entanto, Arroio Grande, assim como foi pelo Brasil, teve episódios marcantes de racismo: como a divisão de locais públicos e privados segundo a raça, como praças e clubes sociais. 
O concurso durou 30 anos, tendo como fundador o professor de História Antônio Carlos da Conceição, conhecido como Dé. A idéia surge do conhecimento de um concurso que ocorria em Santa Catarina, o Miss Mulata Blumenau. O concurso de Arroio Grande teve inicio em âmbito de Zona Sul, e a partir dos anos de 1980, passa a ser Estadual, Miss Mulata Rio Grande do Sul. Ao perguntar sobre a utilização do termo mulata, o Dé responde que é um mulato de mãe negra, a qual sofreu preconceito racial pela família do marido branco. Ele reforça uma postura positivada de sua mãe, uma forma de silenciar estereótipos pejorativos sobre a mulher negra, como: "uma coisa que vou dizer pra vocês é que a minha mãe era uma negra muito bem vestida."

O objetivo do concurso, segundo ele, era de valorizar a beleza da mulher negra, "Valorizar e mostrar que negro é gente né!". O concurso tinha três etapas de avaliação, em que não consistia apenas a beleza. Primeiramente era realizado um coquetel para apresentar as candidatas, no qual a avaliação era comportamental, o modo de sentar, comer e falar. E por fim, no dia do evento, mais dois desfiles, novamente de maiô, e outro com vestido de gala.

Sobre concursos de beleza:

Somente numa sociedade em que a aparência tornou-se estratégia social de poder que toda a atenção, mística e glamour que envolviam os concursos locais e internacionais, para a eleição de uma beleza representativa de um país, de uma cidade, de um clube ou de um evento qualquer, se tornaram justficáveis. (SANT'ANNA, p.3)

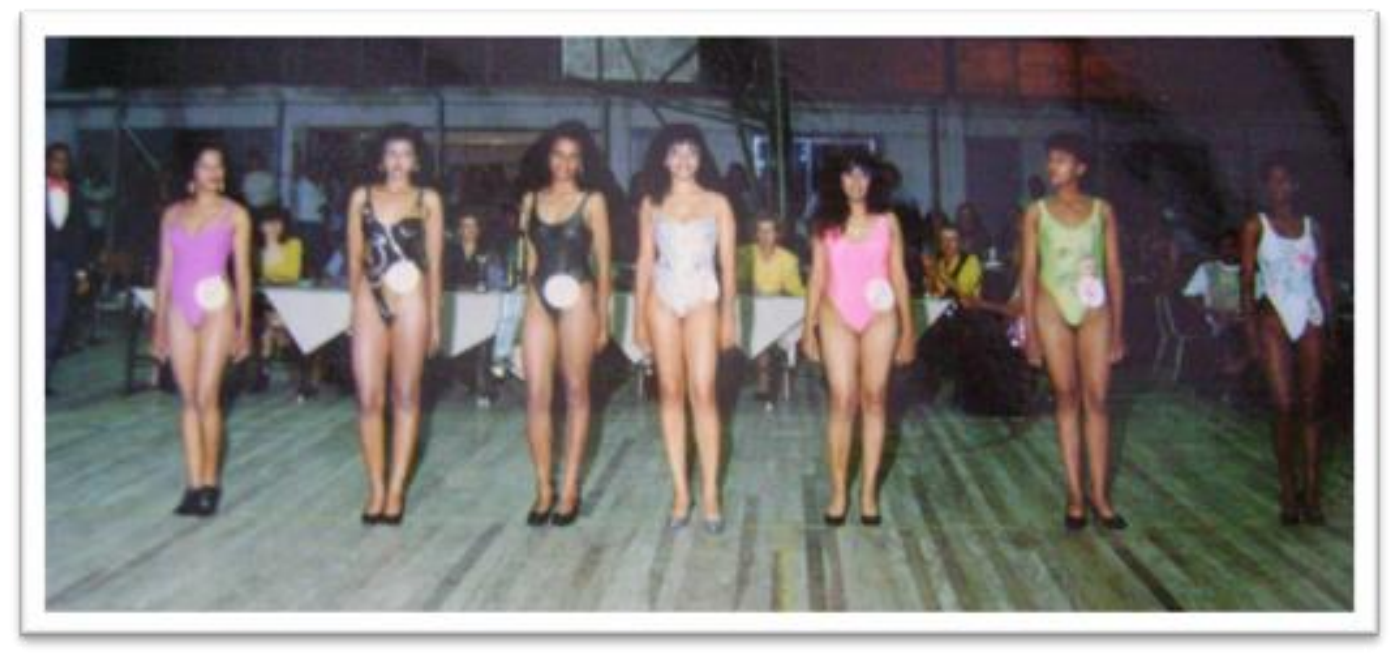

Figura 1- Desfile de maiô: Miss Mulata Rio Grande do Sul 1992

Fonte: Acervo pessoal. 


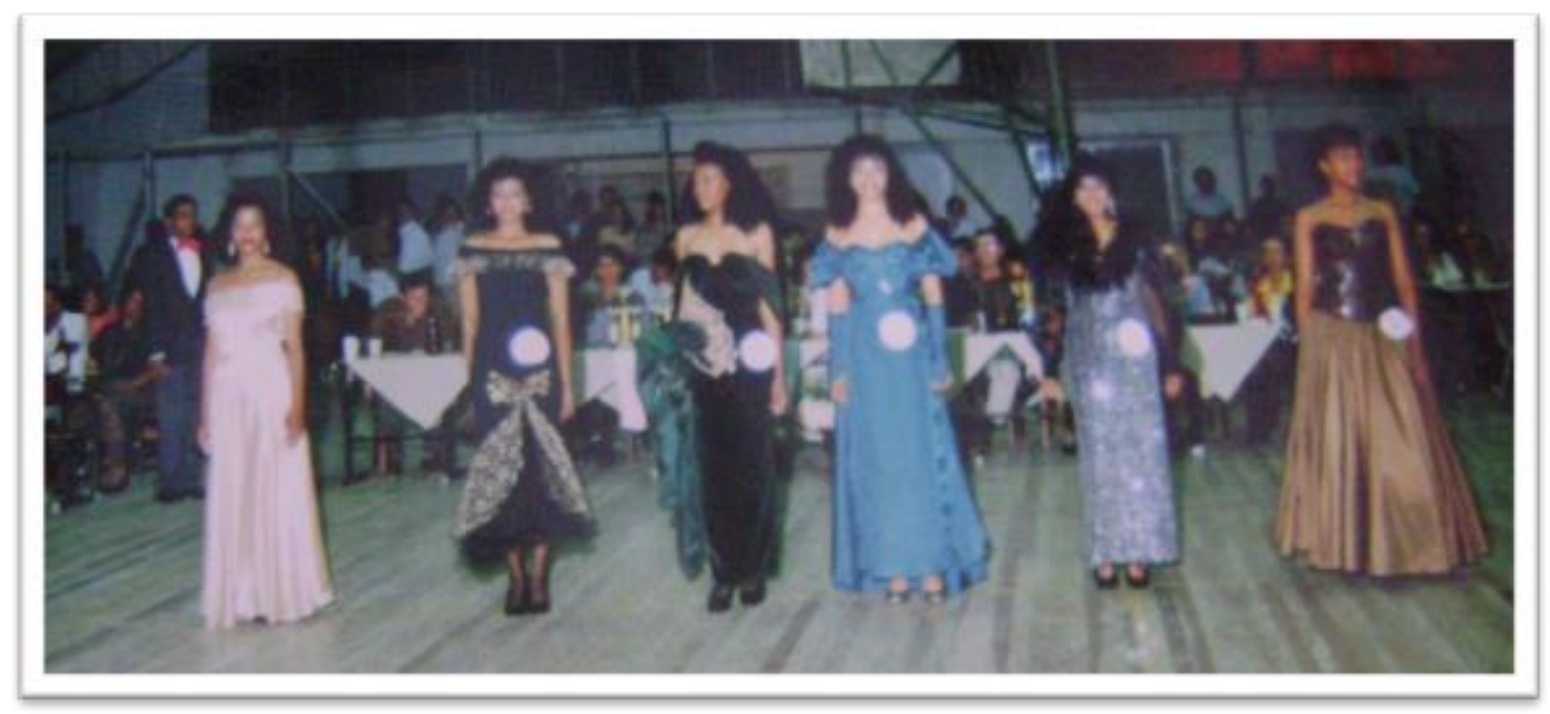

Figura 2- Desfile de Gala: Miss Mulata Rio Grande do Sul 1992

Fonte: Acervo Pessoal

Os concursos também constroem uma imagem do belo, instituem valores, comportamentos. Além disso, a beleza regula distinções e visibilidades sociais. É neste âmbito de aparências e visualizações sociais por meio de concursos de beleza que o Miss Mulata também vai se constituir, perante um grupo que visava as mesmas aspirações: visualidade e valorização. Neste caso, mais específico, devido às construções representativas sobre o corpo e estética da mulher negra ou mulata, sobretudo, moral e sexual (GIACOMONI, 2006). Por isso, a importância destes concursos para a auto-estima, sempre ligados a beleza, uma forma de confronto ao racismo, pois "para o negro, o estético é indissociável do político." (GOMES, 2008, p.130). Uma ideia dos principais movimentos negros na história, como, Black is Beautiful, por volta de 1960 e 1970, que vieram na luta pela valorização da estética e beleza negra nos Estados Unidos, que influenciaram também os movimentos negros no Brasil. O movimento buscava a valorização cultural e suas raízes com a África. É também este o período da tese de crioulização em que estas formas culturais especificamente de seguimentos afros, são na verdade uma recriação, um sincretismo no Novo Mundo, com idealizadores como Mintz e Price, na defesa de uma cultura afro-americana e um protagonismo negro.

É importante ressaltar as diferenças da entrevistadora com suas fontes de entrevista, no que tange raça, cor e idade, ou seja, a maioria dos entrevistados narrou suas memórias a uma 
jovem historiadora não negra. Provavelmente foi relevante para a exposição das narrações, assim como para a postura da entrevistadora, que deve perceber esta diferença, e jamais negála. E que percebe as construções naturalizadas historicamente sobre a supervalorização do branco sobre o corpo negro, e o quanto isto acaba significando perante sua representação enquanto branca. $\mathrm{O}$ trabalho pretende-se enquanto uma agência anti-racista ao explicitar estas construções no que tange raça, cor, beleza e branquitude.

A principal metodologia utilizada é a História Oral. Há uma relação, entre entrevistador e entrevistado, sobre questões referentes às construções, imagens e status. "Enquanto os historiadores estão interessados em reconstruir o passado, os narradores estão interessados em projetar uma imagem.” (PORTELLI, 2004, p.300). Obviamente que a narração não é a realidade "verdadeira", no sentido de não haver intenções ou esquecimentos, sejam eles propositais ou não. É importante ressaltar a presença do entrevistador, ou o gravador, câmera que podem influenciar a certas respostas, ou intimidações.

Através das entrevistas realizadas ficou clara a forte representação deste concurso para estas mulheres. Ao perguntar as candidatas entrevistadas o motivo que levaram a participar do concurso, tem-se a questão de visualização e status, segundo elas, era um luxo, carro particular, cabeleireiro, manto, coroa e buquê de flores. Gerava a auto-estima para estas. Colocando a beleza do cabelo crespo, da pele negra, suas representações de identidade em destaque. Uma delas destaca que:

"Pra gente era uma maravilha, era o auge. Era um status amais." (Katerine Bretanha, Miss Mulata Arroio Grande 1999)

As noções de beleza são historicamente construídas, é também uma agência do poder sobre corpos, em que o padrão estético definido e naturalizado é o branco eurocêntrico.

O conceito de beleza é subjetivo, localizado, histórico e relacional. Apesar dessa relativização, as sociedades impõem alguns padrões de beleza, uma vez que ela também é construída em contextos de relações assimétricas de poder. O corpo é uma das instâncias sujeitas à inscrição, à classificação e a hierarquização da idéia de beleza. Na sociedade brasileira, o padrão assimilado desde o século XVI, como decorrência da colonização portuguesa, possui um viés eurocêntrico. (GOMES apud OLIVEIRA, 2010, p.92)

Os corpos são submetidos à tabus, e é em nome de certos valores que ele se valoriza (BIROLI, 2013), por vezes valores negados a certos grupos, como o das mulheres negras. "Não ter confiança no próprio corpo é perder confiança em si próprio" (BEAUVOIR apud 
BIROLI, 2013, p. 86), e mais, “envergonhar-se do corpo é parte da renúncia à liberdade e aos prazeres.” (BIROLI, 2013, p. 86).

Para algumas candidatas entrevistadas a terminologia mulata se referia à mistura de negros e brancos, e muitas delas tinham pais ou mães brancas. Também tem as que hoje se denominam negras, e já não concordam mais na utilização da terminologia, mas afirmam a importância do concurso como uma referência contra o preconceito.

\section{A construção do bom e do belo: a branquitude normativa}

É sobre o corpo e a estética que se deu o processo da branquitude, criando um padrão preferencial sobre a cor da pele, o formato do nariz e a cor do cabelo. A branquitude é o fenômeno da supervalorização do branco, uma posição de poder, característica de países colonizados pelos europeus, em um ideal eurocêntrico (SOVIK, 2009). Neste contexto as identidades " são delimitada discursivamente não só pelo novo foco no negro e no problema da discriminação racial, ou pela mais antiga proposta da mestiçagem como solução de conflitos, mas pelo processo, impulsionado e naturalizado por uma inércia secular, de supervalorização do branco.” (SOVIK, 2009, p.18)

Este fenômeno está ligado a uma hierarquização dos seres, também, pelo fenótipo. O mestiço neste contexto é ligado ao genético como universal, mas não na prática social.

“[...] a imagem e a autoimagem são muito importantes e não podem mais ser separadas. Internacionalmente, o projeto do Brasil mestiço que contesta a supremacia branca estrangeira esbarra na evidente hipervalorização da branquitude, internamente, e na crescente hibridação de populações e culturas nos centros metropolitanos." (SOVIK, 2009, p.75).

O hibridismo não se refere à composição racial mista, mas a uma lógica cultural e diaspórica, um modo de transformação e transitório, assim como ambíguo e negociável, ou seja, adoção de identificações deslocadas (HALL, 2013). Não se questiona aqui a mestiçagem existente no Brasil, mas nega-se que se vive em um país da democracia racial, pois o racismo ainda é um fato.

O mestiço no século XIX é condenado à degeneração, no Brasil vai se destacar a figura de Silvio Romero, com base nas ideias de um naturalismo evolucionista, junto às posições de Haeckel, Darwin e Spencer; Romero, ao contrario de muitos estudiosos brasileiros, acreditava ver na mestiçagem a saída para uma possível homogeneidade nacional. Estaria no mestiço à vitória do branco no país, o produto de uma raça em formação (SCHWARCZ,1993). 
Nos anos de 1930 se tem o mestiço como símbolo nacional, sobre uma crença de democracia racial. A estratégia de dominação era a da inclusão, e não mais da exclusão como nos Estados Unidos, buscando integrar ao nacional no que tange a cultura de identidades pela miscigenação, negando qualquer identificação unicamente negra.

[...] a elite "pensante" do País tinha clara consciência de que o processo de miscigenação, ao anular a superioridade numérica do negro e ao alienar seus descendentes mestiços graças a ideologia de branqueamento, ia evitar os prováveis conflitos raciais conhecidos em outros países, de um lado, e, por outro, garantir o comando do País ao segmento branco [...] (MUNANGA, 2008, p.75)

Entre os séculos XIX e XX, teve-se a construção de um Brasil sobre o ideal de branqueamento da sociedade. Em que se utilizou da política de imigração européia, aplicada intensivamente no Rio Grande do Sul.

"Muitos intelectuais passaram a postular que o progresso e a civilização do país passariam pelo embraquecimento da população, visto que as características físicas seriam um reflexo moral dos indivíduos. O fenótipo não- branco representava, na visão de intelectuais comprometidos com o projeto das elites, a selvageria e o barbarismo presentes na sociedade brasileira, logo, um retrocesso à modernidade." (PINTO, 2010, p. 35)

A mestiça se dá como um "produto da transculturação, sincretismo e diasporização que criam disjunturas entre tempo e espaço (a fronteira) e deslocamentos dos discursos sobre ‘origens' e essências” (COSTA, 2005, p.695). Ou seja, a mestiça enfrenta uma luta de fronteira, um confronto de duas raças. Ressaltando que a utilização da nomenclatura raça neste trabalho consiste na ligação de fatores sociais, históricos e político ideológico, não mais um conceito com base no biológico, como se percebe no senso comum ainda presente. Segundo Anzaldúa, "o trabalho de consciência mestiza é o de desmontar a dualidade sujeitoobjeto que a mantém prisioneira [...] A resposta para o problema entre a raça branca e a de cor, entre homens e mulheres [...]" (2005, p.707).

E é no âmbito de erotização do corpo feminino que se vai persistir, por parte da elite branca, na invenção da mulata, junto ao samba, carnaval e sexo. Originando um conflito maior ainda sobre a mulher negra, pois são seus símbolos de identidade que estão estereotipados, e excluídos de conceitos sociais, culturais e de beleza.

A branquitude normativa é a idéia que coloca o branco como legítimo ser humano, dotado de superioridade sobre todas as espécies, o que, consequentemente, desumaniza o indivíduo negro, o principal meio de dominação colonial. A regulação social se faz sobre o corpo, e também, sobre o padrão estético. 
Alberto Guerreiro Ramos propôs nos anos 50 do século XX uma discussão acerca de negros como objetos de estudos de brancos, e atestou estes estudos como uma forma de assegurar a brancura, e, assim, fazer parecer que apenas negros tem uma raça, e que essa precisa, então, ser estudada. Mas o termo branquitude é utilizado pela primeira vez no Brasil por Gilberto Freyre, mas de maneira crítica, tendo em vista o seu ideal de democracia racial e defesa da mestiçagem.

Ser branco está no corpo, no visível, mas também consiste em privilégios simbólicos e materiais, "no Brasil ser branco, está ligado à aparência, ao status, e ao fenótipo" (SCHUMAN, 2014, p. 84).

O fato de os estereótipos negativos estarem diretamente associados à cor e a raça negra fez também que os brasileiros mestiços e grande parte da população com ascendência africana, de maneira geral, não se classificassem como negros [...] o que ajudou para que permanecessem intactas todas as estereotipias e representações dos negros. (SCHUCMAN, 2012, p. 44)

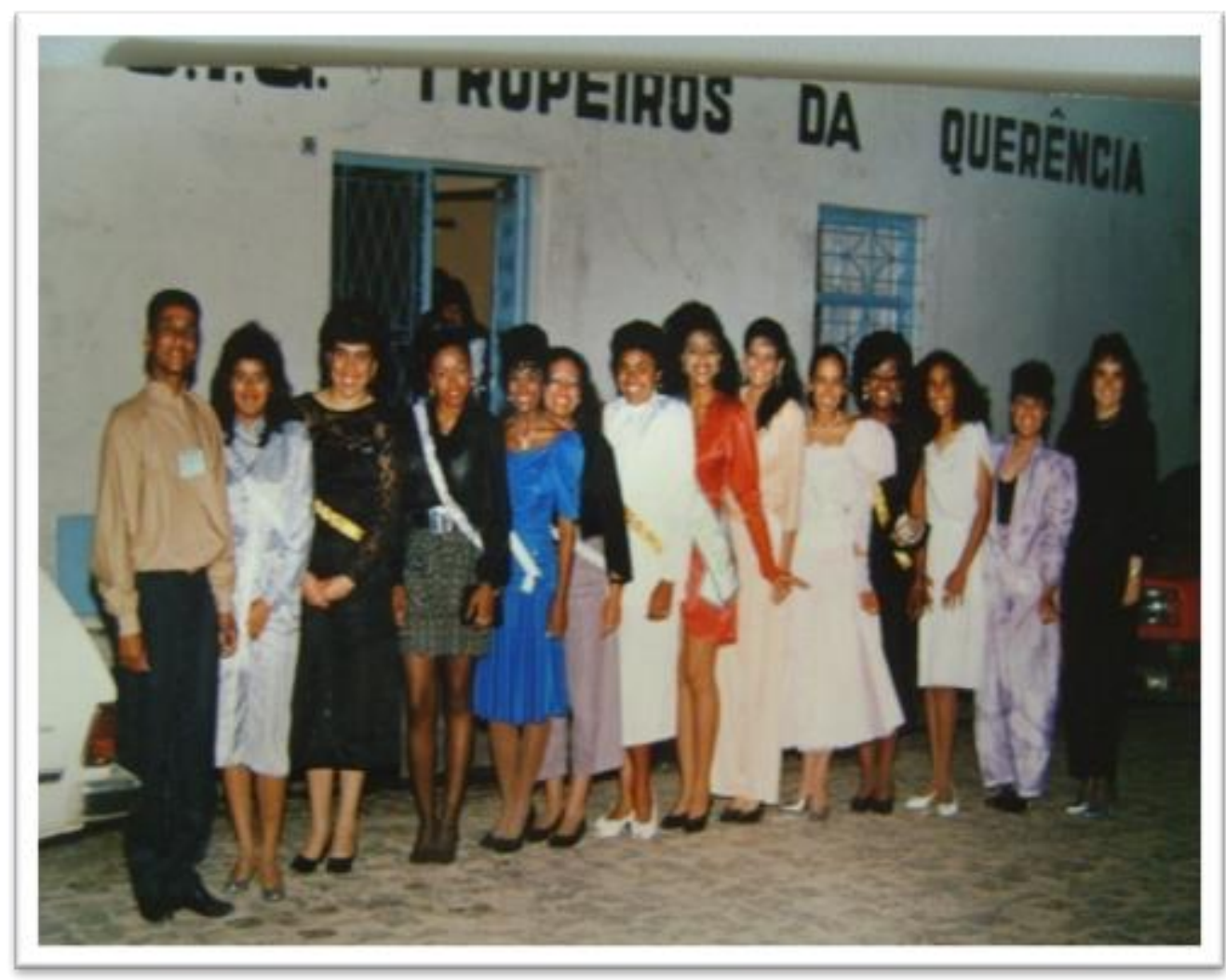

Figura 3- Miss Mulata Rio Grande do Sul 1986

Fonte: Acervo Pessoal 
No concurso Miss Mulata, especificamente, ao analisar fotos e entrevistas, apesar de o concurso ter um caráter de visibilidade, também, para a sociedade branca, ele não silenciou as características negras de suas candidatas, não foram relatados casos de branqueamento, ou a obrigatoriedade de algum estilo de cabelo, pele ou qualquer outra característica. Era necessário ser negra, além da cor da pele, uma questão de descendência, de origem.

Percebe-se que ser negra vai além da cor da pele, é pertencer a uma história comum, também ligada as diásporas, afro- descendência e cultura. E a estética negra também se encontra nesta relação, com base nas entrevistas. Uma candidata expressa bem esta questão ao falar sobre seus objetivos no concurso:

\title{
"valorizar meu potencial cultural, representando a beleza da mulher negra arroio- grandense diante da sociedade brasileira." ( Maria Claúdia da Silva Abreu, Miss Mulata Arroio Grande 1987)
}

O concurso buscava quebrar estereótipos e ir contra a estética padronizada de branquitude, que acaba gerando uma hierarquia sobre negros, em que os de pele mais escura se aproximam da feiúra, e mais claros se afastam.

O sentido, como o da mulata, não é estático e natural, ou seja, é arbitrário e se move pela linguagem, esta por sua vez é um sistema de sinais (HALL, 1997). Tendo o signo uma forma, que pode ser por meio da imagem, fotografia ou palavra; e um conceito ou significado, em que esta forma é associada (HALL, 1997).

Cada um de nós provavelmente entende e interpreta o mundo de um jeito único e individual. No entanto, nós podemos nos comunicar porque compartilhamos praticamente os mesmos mapas conceituais, e, então, tomamos sentidos ou interpretamos o mundo de maneiras grosseiramente iguais. (HALL, 1997, p.5)

Mas Stuart Hall (1997) exemplifica através do termo "preto", enquanto linguagem, a relação de re- apropriação do significado:

\begin{abstract}
Por muitos séculos, sociedades ocidentais associaram a palavra PRETO com tudo o que era escuro, mal, proibido, diabólico, perigoso e pecaminoso. Contudo, pense em como a percepção das pessoas negras na América na década de 60 mudou depois que a frase "Preto é bonito" ("Black is beautiful") se tornou um slogan famoso onde o significante, PRETO, foi levado a significar o sentido exatamente oposto (significado) às suas associações prévias. (HALL, 1997, p.21)
\end{abstract}

Ou seja, levar em conta convenções sociais da sociedade e o momento histórico. "Assim, ao estudar o funcionamento do nome, devemos considerar a presença de toda a história desse nome - não no sentido cronológico, mas como memória de sentidosresponsável por seu sentido no momento do acontecimento.” (LUZ, 2011, p.60) 
O concurso surge em um período de ditadura militar em que não se admitia falar ou denunciar o racismo, então, este era silenciado. Os movimentos negros foram classificados como impatrióticos. Os militares se utilizaram do mito da democracia racial para suprimir a luta anti-racista. Por isso, a palavra negro era uma afirmação perigosa, sendo preciso nomenclaturas mais aceitas, como mulata. A positivação da palavra negro no Brasil é recente, por volta de 1980, e devido às lutas negra, estas negaram palavras como mulata, moreno e pardo como formas de auto-afirmação.

Segundo Schucman (2012), a branquitude também opera nas relações de gênero, colocando a beleza como essência feminina, e para os homens uma questão de status; no comportamento sexual, há uma erotização da mulher negra, enquanto mulheres brancas são presas a castidade; e econômica social, o branco ligado ao dinheiro e beleza, e o negro ligado à pobreza e a favela.

Então, todas estas construções se deram por meio da racialização de gênero e beleza, construções binárias, branco/preto; bonito/feio; bom/mal, uma forma de diferenciar biologicamente e hierquicamente, legitimando um poder sobre o "outro". Com isso, é pela brancura da pele que historicamente se constituiu a branquitude.

\section{Considerações finais}

Assim, como o Miss Mulata, houve outros eventos específicos para uma valorização da mulher negra no Brasil. Como, por exemplo, o Miss Mulata Cheirosa em Belém do Pára, que ocorre durante os festejos Juninos; Concurso de beleza Afro de Campo Largo(de 2008), Paraná; Concursos de Miss do Renascença Clube (anos de 1960), Rio de Janeiro; e do bloco Ilê Ayê da Bahia, que há 36 anos escolhe uma rainha, representando o bloco no evento chamado Noite da Beleza Negra.

Os concursos de beleza negra buscam a valorização destas mulheres em uma sociedade que a exclui do direito de ser bela, mas também, a própria dignidade enquanto ser humano. $\mathrm{O}$ Miss Mulata de Arroio Grande também buscava a valorização de símbolos negros, junto a resignificação da terminologia mulata para ampliar os espaços desta mulher negra dividida entre tais nomenclaturas.

Muitas entrevistadas se autodenominam negras, mas compreendem o período de origem do concurso, em que a crença em uma democracia racial valorizava a mistura, negando qualquer identidade negra. 
Outra característica importante sobre o concurso é a solidariedade, esta caracterizada como vínculo coletivo entre os indivíduos, dando voz a subjetividade, entendendo esta solidariedade racial como fundamento para uma identificação étnico- racial (PINTO, 2010). As entrevistas revelam que candidatas foram arrumadas por mães de suas concorrentes, não se percebe uma disputa acirrada, mas uma solidariedade, enquanto um objetivo em comum, um vínculo coletivo em oposição aos estereótipos atribuídos ao corpo negro.

Enfim, as negativas imagens e o discurso estereotipado sobre o corpo negro foram reapropriados, foi reconstruído para uma identidade do grupo em questão, um enfrentamento à branquitude normativa.

\section{Referências}

BIROLI, Flávia. Autonomia, opressão e identidades: a ressignificação da experiência na teoria política feminista. Estudos feministas, Florianópolis, 21 (1): 424, janeiro- abril/ 2013.

COSTA, Claudia de Lima; ÁVILA, Eliana. Glória Anzaldúa, a consciência mestiça e o feminismo da diferença. Revista Estudos Feministas, 13.3. (2005): 691-703.

FANON, Frantz. Pele negra, máscaras brancas. Salvador: EDUFBA, 2008.

FIGUEIREDO, Ângela. "Cabelo, cabeleira, cabeluda e descabelada": Identidade, Consumo e manipulação da aparência entre os negros brasileiros. XXVI Reuniaão Anual da Associação nacional de Pós- Graduação e pesquisa em Ciências Sociais, Caxambu, Outubro de 2002.

FREYRE, Gilberto. Casa Grande \& Senzala: formação da família brasileira sob o regime da economia patriarcal. São Paulo: Global, 2006.

GIACOMINI, Sonia Maria. A Alma da Festa: família, etnicidade e projetos num clube social da Zona Norte do Rio de Janeiro. O Renascença Clube. Belo Horizonte: Editora UFMG; Rio de Janeiro, IUPERJ, 2006.

GUIMARÃES, Antônio Sérgio Alfredo. Preconceito Racial: modos, temas e tempos. 2 ed. São Paulo: Cortez, 2012.

GOMES, Nilma Nilo. Sem Perder a Raíz: Corpo e cabelo como símbolos da identidade negra. Belo Horizonte: Autêntica, 2008.

HALL, Stuart. Da diáspora: identidades e mediações culturais. 2ed. Belo Horizonte: Editora UFMG, 2013. 
HALL, Stuart. The work of representation. In: HALL, Stuart (Org.) Representation:

Cultural representation and cultural signifying practices. London/Thousand Oaks/New Delhi: Sage/Open University, 1997. Pág. 15-64

LUZ, Marcelo Giovannetti Ferreira. A nomeação como procedimento de constituição da identidade negra nos discursos sociais e nos documentos oficiais do Estado: um silenciamento da miscigenação. Dissertação de Mestrado. São Carlos: UFSCar, 2012.

MUNANGA, Kabengele. Negritude: Usos e Sentidos. 3.ed, Belo Horizonte: Auntêntica Editora, 2012.

MUNANGA, Kabengele. Rediscutindo a mestiçagem no Brasil: identidade nacional versus identidade negra. 3ed. Belo Horizonte: Autêntica, 2008.

MUNANGA, Kabengele. Uma abordagem conceitual das noções de raça, racismo, identdade e etnia. IN: Palestra proferida no $3^{\circ}$ Seminário Nacional Relações Raciais e Educação-PENESB-RJ, 05/11/03.

OLIVEIRA, Carolina dos Santos de. Adolescentes Negras: relações raciais, discurso e mídia impressa feminina na contemporaneidade. Belo Horizonte: Nandyala, 2010.

PINHO, Osmundo de Araújo. O efeito do sexo: políticas de raça, gênero e miscigenação. Cadernos Pagu (23), Julho- Dezembro de 2004, p.89-119.

PINTO, Nubia dos REIS. Ascensão social negra: do branqueamento à solidariedade. Dissertação de mestrado. Bahia: UFB, 2010.

PORTELLI, Alessandro. 'O momento da minha vida': funções do tempo na história oral. In: FENELON, Déa Ribeiro et. al. (Org.). Muitas memórias, outras histórias. São Paulo: Olho d'Água, 2004, p. 296-313

SANTA’ ANNA, Denise Bernuzzi de. História da beleza no Brasil. São Paulo: Contexto, 2014.

SCHUCMAN, Lia Vainer. Entre o "encardido", o "branco" e o "branquíssimo": raça, hierarquia e poder na construção da branquitude paulistana. Tese de doutorado. São Paulo: USP, 2012.

SCHUCMAN, Lia Vainer. Sim, Nós somos racistas: Estudo Pisicossocial da Branquitude paulistana. Piscicologia e sociedade, 26 (1), 2014, 83-94. 
SCHWARCZ, Lilia Moritz. O espetáculo das raças: cientistas, instituições e questão racial no Brasil- 1870-1930. São Paulo: Companhia das Letras, 1993.

SOVIK, Liv. Aqui ninguém é branco. Rio de Janeiro: Aeroplano, 2009.

WEIMER, Rodrigo. Ser "moreno", ser "negro": memórias de experiência de racialização no litoral norte do Rio Grande do Sul no século XX. Est. Hist., Rio de Janeiro, v, 26, n 52 , p. 409-428, julho-dezembro de 2013. 